\title{
SISTEM DAN ANALISIS PEMASARAN IKAN PELAGIS DI TEMPAT PELELANGAN IKAN MUARA ANGKE, JAKARTA UTARA
}

\author{
Hardino Wijaya Putra ${ }^{1)}$, Ediyanto ${ }^{2)}$ \\ ${ }^{1,2,)}$ Program Studi Pemanfaatan Sumberdaya Perairan \\ FPIK USNI \\ Jl. Arteri Pondok Indah No.11 Kebayoran Lama Jakarta \\ Hardinoputra@yahoo.com
}

\begin{abstract}
ABSTRACK
This study aims to identify the form of marketing channels and institutions involved in the marketing of small pelagic fishes at Muara Angke Fish Auction Places. Calculates Margin Analysis and Fisherman Share Analysis at each marketing agency involved. And know the flow of Fish Marketing in Muara Angke. The results of this research have 3 plot seprti, groove 1, groove 2 and groove 3, where the groove 1 includes Fisherman-TPI-Consumer, groove 2 includes Fisherman-TPI-Retailer-Consumer and last 3 grooves include Fishermen-TPI-Indutri-Konsumen.
\end{abstract}

Keywords: Small Pelagic Fish, Margin, Fisherman, Marketing Chain, Marketing Flow.

\section{PENDAHULUAN}

\section{Latar Belakang}

Indonesia memiliki potensi sumberdaya perikanan laut yang beragam dan melimpah pada lautnya mencapai luas sekitar 5,8 juta $\mathrm{km}^{2}$. Estimasi potensi sumberdaya laut Indonesia pada tahun 2016 mencapai 6,83 juta ton atau 103,82\% dari target terbesar 6,58 juta ton, jenis ikan hasil tangkapan di perairan laut sebagian besar adalah ikan cakalang (skipjack tuna), layang (scad), kembung (short-bodied mackel), madidihang (yelowfin tuna), dan tongkol krai (friget tuna) (Kementerian Kelautan dan Perikanan, 2016).

Di Indonesia sumberdaya ikan merupakan salah satu sumberdaya perikanan yang paling melimpah Merta, et al (1998) dalam Norita, (2011) dan paling penting banyak ditangkap untuk dijadikan konsumsi. Potensi ikan laut Indonesia diperkiraan sebesar 6,4 juta ton per tahun, dimana sekitar 73,43\% atau 4,7 juta ton diantaranya adalah dari kelompok ikan pelagis, baik itu ikan pelagis besar maupun pelagis kecil. Potensi ikan pelagis diperkiraan sekitar 3,6 juta ton per tahun atau 56,25\% dari potensi ikan secara keseluruan, dan baru dimanfaatan sekitar 49,50\% (Suyasa, et al, 2007).

Pelabuhan perikanan adalah suatu lingkungan kerja yang salah satu fungsinya sebagai pusat pemasaran dan distribusi pemasaran. Fungsi tersebut menjelaskan bahwa hal yang didapat para nelayan dilelang di tempat pelelangan ikan agar mendapatkan situasi yang stabil, suatu saat akan meningkat atau akan menurun secara drastis. Dengan demikian nelayan-nelayan yang mendaratkan hasil tangkapannya, merasa diuntungkan dengan ada pelelangan ikan. Pelelangan ikan 
merupakan salah satu aktivitas penting sebagai awal penting dari pemasaran ikan di pelababuhan perikanan, sehingga para nelayan diuntungkan dengan adanya aktivitas ini.

Pangkalan Pendaratan Ikan (PPI) Muara Angke adalah salah satu Pelabuhan Perikanan tipe D yang terdapat di Jakarta Utara yang memiliki potensi perikanan cukup besar dan memiliki potensi pemasaran yang cukup baik. Dalam kegiatannya, PPI Muara Angke tidak pernah lepas hubungannya dengan koperasi. Koperasi perikanan Mina Jaya adalah koperasi yang sangat berperan dalam penyelenggaraan pelelangan ikan di PPI Muara Angke dan berperan juga terhadap pengelolaan retribusinya. Pelabuhan Pendaratan Ikan Muara Angke dalam memasarkan produksinya dengan menggunakan sistem lelang murni, dimana juru lelang menyebutkan harga yang akan terus naik hingga hanya terdapat satu calon pembeli atau bakul yang setuju (Yustiarani, 2008).

Fasilitas untuk pedagang pengecer di Muara angke diberikan dalam rangka memberikan pelayanan kepada masyarakat yang memerlukan ikan dalam jumlah kecil. Luas pasar pengeceran $1.260 \mathrm{~m}^{2}$ dengan jumlah lapak 150 buah yang di manfaatkan oleh 180 orang. Pasaran pengeceran ini melayani kebutuhan konsumen dan para pengunjung yang akan mengkonsumsi ikan bakar di pusat jajan serba ikan yang masih berada di kawasan Muara angke. Omset penjualan pengecer di pasar dalam seminggu dapat mencapai $500 \mathrm{~kg} /$ pedagang, dengan jumlah produksi tersebut perlu senantiasa menjaga mutu dan kesegaran ikan hasil tangkapan agar tetap terjaga kesegaran hingga di tangan konsumen (Norita, 2011).

Menurut Harifuddin et al. (2011) bahwa produksi yang tinggi dapat mendorong terlaksananya kegiatan pemasaran yang melibatkan beberapa lembaga pemasaran. Ismail et al (2008) menambahkan bahwa pemasaran merupakan kegiatan yang penting dalam menjalankan usaha perikanan, karena pemasaran merupakan tindakan ekonomi yang berpengaruh terhadap naik turunnya pendapatan nelayan. Produksi akan sia-sia bila harga rendah, maka pemasaran harus baik dan efisien. Triyanti dan Safitri (2012) menjelaskan bahwa pemasaran produk merupakan salah satu komponen pasca produksi yang perlu mendapat perhatian yang lebih karena merupakan kunci dalam pengembangan usaha. Produk perikanan yang bersifat mudah rusak (perisable), mengharuskan pemasarannya membutuhkan perhatian khusus. Menurut Arinong dan Kadir (2008) bahwa saluran pemasaran mempunyai tugas menyalurkan barang dari produsen ke konsumen. Panjang pendeknya saluran pemasaran akan menentukan kualitas produk yang dipasarkan, biaya, margin dan efisiensi pemasaran, serta pendapatan.

Pemasaran merupakan hal yang paling penting dalam menjalankan sebuah usaha perikanan karena pemasaran merupakan tindakan ekonomi yang berpengaruh terhadap tinggi rendahnya pendapatan nelayan. Produksi yang baik akan sia-sia karena harga pasar yang rendah, sehingga tingginya produksi tidak mutlak memberikan keuntungan yang tinggi tanpa pemasaran yang baik dan efisien. Secara umum, pemasaran dapat diartikan sebagai segala kegiatan yang dilakukan oleh berbagai perantara dengan berbagai macam cara untuk menyampaikan hasil produksi, yaitu ikan laut segar, dari produsen ke konsumen akhir.

Menurut Fauziah, (2011) rantai pemasaran merupakan suatu gambaran tentang jalur distribusi penyampaian komoditas dari satu pelaku pemasaran ke 
pelaku yang lain. Berdasarkan rantai pemasaran yang ada dapat diketahui biaya pemasaran yang dilakukan masing-masing pelaku. Rantai komuditas perikanan umumnya pendek dan sedikit melibatkan pelaku pemasaran karena komuditas perikanan harus diolah agar tidak mengalami kerusakan.

\section{METODE PENELITIAN \\ Waktu dan Tempat Penelitian}

Penelitian dengan judul "Analisis Pemasaran Ikan Pelagis Kecil di Tempat Pelelangan Ikan Muara Angke, Jakarta Utara" direncanakan pada bulan Oktober Desember 2016 di TPI Muara Angke.

\section{Alat dan Bahan}

Peralatan dan bahan yang digunakan dalam penelitian ini adalah : Alat tulis, Laptop dan Kamera, sedangkan bahan yang digunakan dalam penelitian ini adalah data dari Tempat Pelelangan Ikan (TPI) Muara Angke.

\section{Metode Penelitian}

Metode Penelitian yang dilakukan adalah metode studi kasus. Penelitian studi kasus harus dilakukan secara dialektik antara bagian dan keseluruhan. Maksudnya, untuk memahami aspek tertentu perlu diperoleh gambaran umum tentang aspek itu. Sebaliknya, untuk memperoleh gambaran umum diperlukan pemahaman bagian-bagian khusus secara mendalam untuk memperoleh pengetahuan secara mendalam, data studi kasus dapat diperoleh tidak saja dari kasus yang diteliti, tetapi juga dari semua pihak yang mengetahui dan mengenal kasus tersebut dengan baik.

\section{Jenis dan Sumber Data}

Jenis data yang dibutuhkan dalam penelitian ini terdiri dari data kualitatif dan data kuantitatif. Data kualitatif adalah untuk melacak biaya dan harga dan data kuantitatif adalah untuk memperjelas bagaimana sistem pemasaran yang ada didalam suatu saluran pemasaran berjalan. Metode pengambilan data pada penelitian ini dikumpulkan dari rangkaian data primer dan data sekunder. Data primer dikumpulkan langsung dari lapangan dalam bentuk wawancara terhadap stake holder (Keluarga nelayan, pedagang ikan, pengurus TPI, pemerintah daerah setempat dan beberapa pihak terkait) dan data sekunder diperoleh dari penelusuran studi literatur, laporan arsip dan dokumen dari dinas perikanan setempat dimana penelitian dilakukan.

\section{Teknik Pengumpulan Data}

Dalam penelitian ini pengambilan data dilakukan dengan cara sebagai berikut:

a) Wawancara langsung dengan nelayan dan lembaga pemasaran (responden) berdasarkan pertanyaan sesuai dengan data yang dibutuhkan.

b) Mencatat dan mengumpulkan data dari responden dan instansi yang terkait dengan penelitian ini.

c) Melakukan observasi yaitu mengadakan pengamatan langsung di lapangan pada setiap obyek dan permasalahan yang diteliti untuk melengkapi data primer dan data sekunder. Analisis Data 


\subsubsection{Analisis Deskriptif}

Analisis deskriptif uraian atau usaha untuk mengetahui arti suatu keadaan data atau bahan keterangan mengenai suatu keadaan dan diselidiki hubungannya satu sama lain. Tujuan analisa deskriptif adalah untuk menyederhanakan data-data ke dalam bentuk yang lebih mudah dibaca dan diinterpretasi.

\section{Analisis Margin Pemasaran}

Margin pemasaran adalah perbedaan harga yang dibayar kepada produsen dan harga yang dibayar oleh konsumen (Hanafiah dan Saefuddin, 2006). Perhitungan analisis margin pemasaran dilakukan untuk mengetahui perbedaan harga persatuan ditingkat produsen atau ditingkat konsumen yang terjadi pada rantai pemasaran. Secara matematis dapat dirumuskan sebagai berikut :

\section{Keterangan :}

$\mathrm{Mp} \quad=$ Margin Pemasaran

$\operatorname{Pr} \quad=$ Harga di Konsumen

Pf $\quad=$ Harga di Produsen

\section{Analisis Fisherman's Share}

Analisis ini digunakan untuk membandingkan harga yang diterima produsen dengan harga yang dibayarkan oleh konsumen akhir bisa disebut dengan Fisherman's Share (Hanafiah dan Saefuddin, 2006). Fisherman's Share berhubungan negatif dengan margin pemasaran, semakin tinggi pemasaran maka bagian yang akan diperoleh produsen semakin rendah. Secara matematis Fisherman's Share dapat dirumuskan sebagai berikut.

Keterangan:

Fs $=$ Persentase yang diterima oleh nelayan

Pf = Harga di tingkat nelayan

$\operatorname{Pr}=$ Harga di tingkat konsumen.

\section{HASIL DAN PEMBAHASAN}

Nelayan pemilik adalah orang atau badan hukum yang dengan hak apapun berkuasa atas sesuatu kapal/perahu yang dipergunakan dalam usaha penangkapan ikan dan alat-alat penangkapan ikan. Kapten kapal adalah seseorang nakoda tertinggi dikapal yang tau kemana arah tujuan tersebut dan ABK adalah Anak Buah Kapal atau Awak Kapal, yaitu semua orang yang bekerja dikapal, yang bertugas mengoperasikan dan memelihara serta menjaga kapal dan muatan, Anak Buah Kapal (ABK) terbagi dalam beberapa jabatan sesuai dengan tugas dan tanggung jawab masing-masing. Pada umumnya satu awak kapal terdiri dari satu nahkoda, satu wakil nahkoda, satu juru mesin, satu wakil juru mesin dan nelayan buruh lainnya. Nahkoda mempunyai tugas serta tanggung jawab yang paling besar terhadap kelancaran operasi penangkapan ikan. Jumlah dan Status Nelayan di Kelurahan Pluit dapat dilihat pada Tabel 4. 
Tabel 4. Jumlah dan Status Nelayan di Pelabuhan Muara Angke Tahun 2016.

\begin{tabular}{|l|l|l|l|}
\hline No & Stasus Nelayan & Jumlah (Orang) & Persentase (\%) \\
\hline 1 & Nelayan Pemilik & 354 & 78 \\
\hline 2 & kapten Kapal & 30 & 7 \\
\hline 3 & ABK & 70 & 15 \\
\hline & Jumlah & 454 & 100 \\
\hline
\end{tabular}

Sumber : Pelabuhan Muara Angke 2016.

Jumlah nelayan tetap yang ada di Muara Angke pada tahun 2016 lebih banyak dibandingkan dengan jumlah nelayan pemilik, yaitu 354 orang dengan presentasi (78\%), ABK yaitu 70 orang dengan presentasi 15\% dan 30 kapten kapal dengan presentase $7 \%$ dan Total keseluruhan status nelayan pemilik sampai ABK sebanyak 454 orang dengan presentasi $100 \%$.

\section{Harga ikan}

Harga ikan di Muara Angke seperti ikan kembung, ikan layang, ikan layur, ikan lemuru, ikan selar dan ikan tongkol bervariasi baik itu di nelayan, TPI, pengecer dan industri.

Harga rata-rata ikan pada setiap pelaku perikanan memiliki harga yang berbeda, pada umumnya harga tersebut dipengaruhi karena panjangnya alur pemasaran ikan yang melibatkan para pelaku perikanan. Faktor lain yang menjadi alasan naik atau turunnya harga ikan di Tempat Pelelangan Ikan Muara Angke adalah pengaruh cuaca ketika melakukan operasi penangkapan menjadi kendala utama bagi para nelayan karena mempengaruhi jumlah hasil tangkapan yang didapatkan oleh para nelayan.

\section{Analisis Margin Pemasaran}

Margin Pemasaran sering digunakan sebagai indikator efisiensi pemasaran. Besarnya margin pemasaran pada berbagai saluran pemasaran dapat berbeda, karena tergantung pada panjang pendeknya saluran pemasaran dan aktivitas yang telah dilaksanakan serta keuntungan yang didapatkan. Untuk itu digunakan konsep margin pemasaran pada saluran pemasaran pada Tahun 2016 di TPI Muara Angke

perhitungan margin pemasaran pada saluran pemasaran I didapatkan dari total penjualan rata-rata di TPI sebesar $\mathrm{Rp} 82.623$ dikurangi dengan total penjualan rata-rata nelayan sebesar $\mathrm{Rp} 71.623$ maka margin pemasaran saluran pertama sebesar Rp 11.000.

saluran pemasaran II di atas untuk TPI dengan total penjualan rata-rata sebesar $\mathrm{Rp} 82.623$ dikurangi dengan total penjualan rata-rata nelayan sebesar Rp 71.623 maka margin pemasaran sebesar $\mathrm{Rp} 11.000$, dan untuk margin pemasaran pengecer terhadap TPI sebesar Rp 36.024 diperoleh dari total penjualan rata-rata pengecer sebesar Rp 118.647 dikurangi dengan total penjualan rata-rata TPI sebesar Rp 82.623 dan marjin pemasaran dari pengecer sebesar Rp 36.024.

saluran pemasaran III di atas untuk TPI dengan total penjualan rata-rata sebesar Rp 82.623 dikurangi dengan total penjualan rata-rata nelayan sebesar Rp 71.623 maka margin pemasaran sebesar Rp 11.000, dan untuk margin pemasaran 
Industri Pengolahan terhadap TPI sebesar Rp 23.025 diperoleh dari total penjualan rata-rata industri pengolahan sebesar Rp 105.673 dikurangi dengan total penjualan rata-rata TPI sebesar Rp 82.623.

Dari perhitungan ketiga margin pemasaran diatas masing-masing total margin pemasaran pada saluran pemasaran pertama sebesar Rp 11.000, total margin pemasaran saluran pemasaran kedua sebesar Rp 47.024 dan total margin pemasaran pada saluran pemasaran ketiga sebesar $\mathrm{Rp} 34.050$, jadi bisa disimpulkan bahwa total margin pemasaran pada saluran pemasaran kedua lebih besar dibandingkan dengan total margin saluran pemasaran lainnya. Hal ini dikarenakan pada saluran pemasaran kedua terdapat pedagang pengecer yang dimana menjadi faktor pembeda dibandingkan dengan saluran pemasaran yang lainnya, hal ini disebabkan karena kualitas ikan segar yang dijual pedagang pengecer menjadi faktor keunggulan utama dibandingkan dengan produk olahan yang dijual oleh industri pengolahan pada umumnya sehingga hal tersebut mempengaruhi harga jual yang diberikan oleh pedagang pengecer.

\section{Analisis Fisherman's Share}

Fisherman share merupakan harga yang diterima oleh nelayan dengan harga yang dibayaran oleh konsumen akhir. Fisherman's share berhubungan negatif dengan margin pemasaran, artinya semakin tinggi marjin pemasaran maka bagian yang akan diperoleh nelayan semakin rendah.

Beradasarkan perhitungan analisis fisherman's share pada setiap saluran pemasaran.

Saluran pemasaran pertama dengan harga yang ditentukan oleh nelayan sebesar Rp 71.623 dan harga yang ditentukan TPI sebesar Rp 82.623 maka Fisherman's Share yang diperoleh nelayan sebesar $87 \%$, sedangkan pada saluran pemasaran kedua dengan harga yang ditentukan nelayan sebesar Rp 71.623 dan harga yang ditentukan pedagang pengecer sebesar Rp Rp 118.647 maka Fisherman's Share yang diperoleh nelayan sebesar 60\%, dan pada saluran pemasaran ketiga dengan harga yang ditentukan nelayan sebesar Rp 71.623 dan harga yang ditentukan industri pengolahan sebesar Rp 105.673 maka Fisherman's Share yang diperoleh nelayan sebesar $68 \%$. Dari hasil perhitungan Fisherman's Share ketiga saluran pemasaran diatas persentase bagian yang diterima nelayan dari TPI sebesar $87 \%$ adalah persentase terbesar dari persentase perhitungan Fisherman's Share lembaga pemasaran yang lainnya. Jadi dapat disimpulkan dari perhitungan Fisherman's Share ketiga saluran pemasaran tersebut, lembaga pemasaran TPI memegang peranan penting dalam bagian hasil yang diterima oleh nelayan. Hal ini disebabkan karena lembaga pemasaran TPI adalah titik temu awal pertama terjadinya proses pemasaran pada saluran pemasaran yang ada di pelelangan ikan muara Angke.

\section{Rantai Pemasaran Ikan}

Hasil pemasaran PPI Muara Angke tidak memiliki rantai pemasaran yang panjang karena ikan hasil tangkapan pada umumnya akan langsung dijual ke pedagang pengecer atau dapat dibeli langsung oleh para konsumen, Walaupun di Muara Angke terdapat tempat pelelangan ikan (TPI), tempat ini digunakan dengan baik dan banyak ikan yang di daratkan di tempat pelelangan ikan (TPI). 
Rantai pemasaran atau tata niaga hasil tangkapan nelayan Muara Angke terbagi menjadi tiga alur pemasaran dan dapat dilihat pada Gambar 7.

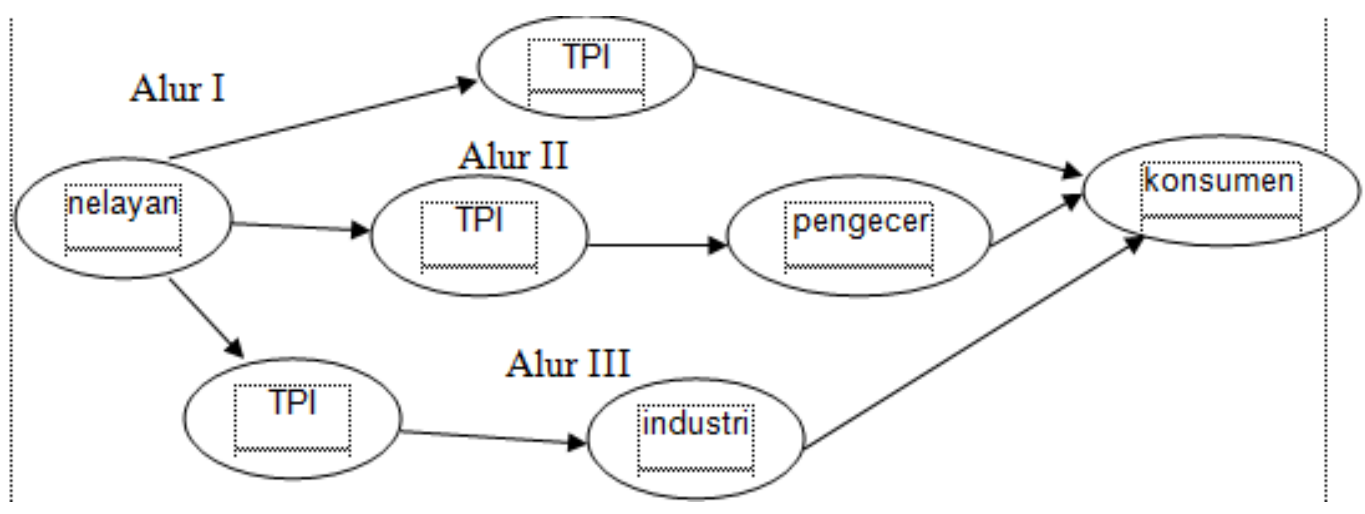

\section{Keterangan : Alur I : Nelayan - TPI - Konsumen Alur II : Nelayan - TPI - Pengecer - Konsumen Alur III : Nelayan - TPI - Industri - Konsumen}

\section{Gambar 7. Rantai Pemasaran Ikan di PPI Muara Angke}

Rantai pemasaran di PPI Muara Angke terdiri dari:

- Nelayan orang-orang yang sehari-harinya bekerja menangkap ikan atau biota lainnya yang hidup di dasar, kolom maupun permukaan perairan.

- TPI adalah sebuah pasar yang biasa terletak di pelabuhan atau pangkalan pendaratan ikan dan di tempat tersebut terjadi transaksi penjualan ikan dan hasil laut baik secara lelang maupun tidak.

- Pengecer adalah adalah Organisasi ataupun seseorang yang menjalankan penjualan barang secara langsung ke konsumen akhir untuk penggunaan pribadi dan bukan bisnis. Pada prakteknya pengecer melakukan pembelian barang ataupun produk dalam jumlah besar dari produsen, ataupun pengimport baik secara langsung ataupun melalui grosir, untuk kemudian dijual kembali dalam jumlah kecil.

- Indutri adalah sebuah tempat yang biasanya ikan dari pelelangan langsung dikirim ketempat industri ikan dan di proses menjadi suatu produk seperti ikan asin, ikan pindang, terasi, kerupik kulit dan pengolahan limbah ikan.

- Konsumen adalah setiap orang pemakai barang dan/atau jasa yang tersedia dalam masyarakat, baik bagi kepentingan diri sendiri, keluarga, orang lain, maupun makhluk hidup lain dan tidak untuk diperdagangkan.

Tataniaga merupakan salah satu faktor yang dapat membantu dan meningkatkan pembangunan pada sektor perikanan. Pemasaran merupakan kegiatan ekonomi dimana terjadi proses penyampaian barang dari produsen kepada konsumen. Dalam proses pemasaran ini terjadi transaksi antara produsen dan konsumen. Kegiatan ini sangat menunjang dan mempunyai peranan penting yaitu untuk meningkatkan perikanan pembangunan daerah. 


\section{KESIMPULAN DAN SARAN}

\section{Kesimpulan}

Berdasarkan penelitian analisis pemasaran ikan pelagis kecil di Tempat Pelelangan Iikan (TPI) Muara Angke Jakarta dapat di simpulkan sebagai berikut:

1. Bentuk saluran pemasaran di Tempat Pelelangan Ikan, Muara Angke terbagi menjadi 3 saluran pemasaran, yaitu:

- Saluran I yang terdiri dari : Nelayan - TPI - Konsumen

- Saluran II yang terdiri dari : Nelayan - TPI - Pengecer - Konsumen.

- Saluran III yang terdiri dari : Nelayan - TPI - Industri - Konsumen.

2. Perhitungan margin pemasaran pada saluran pemasaran I sebesar Rp 11.000. perhitungan margin saluran pemasaran II sebesar Rp 36.024 dan margin pemasaran saluran III sebesar Rp 23.025. Perhitungan Fisherman's Share yang diterima nelayan pada saluran pemasaran I adalah sebesar 87\% dimana hasil persentase tersebut didapatkan dari harga yang ditentukan oleh nelayan sebesar Rp 71.623 dibagi dengan harga yang ditentukan oleh TPI sebesar Rp 82.623, perhitungan Fisherman's Share pada saluran pemasaran II dengan harga yang ditentukan nelayan sebesar Rp 71.623 dan harga yang ditentukan pedagang pengecer sebesar Rp Rp 118.647 maka Fisherman's Share yang diperoleh nelayan sebesar $60 \%$, dan hasil perhitungan Fisherman's Share pada saluran pemasaran III dengan harga yang ditentukan nelayan sebesar Rp 71.623 dan harga yang ditentukan industri pengolahan sebesar Rp 105.673 maka Fisherman's Share yang diperoleh nelayan sebesar $68 \%$.

\section{Saran}

1. Diperlukan upaya baik dari lembaga pengelola perikanan setempat, agar informasi pasar atau alur pemasaran dapat sampai ke konsumen akhir. Inform - : dapat diperoleh dengan dua cara yaitu dari Tempat Pelelangan Ikan dan nelayaı.

\section{DAFTAR PUSTAKA}

Adi. I. 2016. Analisis Pemasaran Ikan hias di Pulau Panggang, Kabupaten Administrasi Kepulauan Seribu.

Apituley. Y. M. T. N. 2013. Model Pengembangan Sistem Pemasaran Ikan Segar di Kawasan Maluku Tengah (Ringkasan disertasi). Sekolah Pascasarjana, Institut Pertanian Bogor. Bogor.

Arinong. A. R. dan E. Kadir. 2008. Analisis Saluran dan Margin Pemasaran Kakao Di Desa Timbuseng, Kecamatan Pattalassang, Kabupaten Gowa. Jurnal Agrisistem Vol. 4, No.2 : $87-93$

Dirktoral Jenderal Perikanan. 1998. Laporan Bulan April Tahun 1998. Departermen

Pertanian Jakarta.

Fauziyah dan Jaya. A. 2010. Densitas Ikan Pelagis Kecil Secara Akustik di Laut Arafura, Jurnal Penelitian Sains, Volume 13 Nomer 1(D) 13106.

Fauziyah. 2011 Integrasi Pasar Ikan Tongkol di PPN Pekalongan dan PPS Nizam Zachman Jakarta, Maspari Journal 03 (2011) 15-19.

Hanafiah. A.M. dan A.M. Saefudin, 2006. Tata Niaga Perikanan . UI Press. Jakarta. 
Handayani. S. M dan Minar, F. 2000. Integrasi Pasar Antar Wilayah Dalam Pemasaran Ubi Kayu Di Daerah Yogyakarta. Penelitian Kelompok dalamBidang Pertanian. UNS Press. Surakarta.

Harifuddin. Aisyah, dan Budiman. 2011. Analisis Margin dan Efisiensi Pemasaran Rumput Laut di Desa Mandalle Kecamatan Mandalle, Kabupaten Pangkep. Jurnal Agribisnis Vol.10 No.3 : 37 - 48.

Ismail G. S. Supardi, dan S. Wahyuningsih. 2008. Analysis Efficiency Marketing System of Fresh Layang Fish (Decapterus russeli) on Pelabuhan Fish Auction Place in Tegal City. Jurnal MEDIAGRO 39 Vol. 4 No. $2: 39$ - 50

Komisi Nasional Stok Sumber Data Ikan Laut. 1998. Potensi dan Penyebaran Sumberdaya Laut di Peraian Indonesia. LIPI. Jakarta.

http://kkp.go.id/wp-content/uploads/2017/07/LAPTA\%20KKP\%202016.pdf

Mukhsin. I. 2003. Pengelola Sumberdaya Hayati Pesisir dan Laut. Jurusan Manajemen Sumberdaya Perairan Fakultas Perikanan Dan Ilmu Kelautan Institut Pertanian Bogor.

Norita. 2011. Studi Kadar Kesegaran (TVB-N) Ikan Kembung (Rastrelliger spp) di Tempat Pelelangan Pendaratan Ikan (TPI) dan Pasar Pengeceran Muara Angke Jakarta Utara.

Perdana. R. H. 2015. Analisis Rantai Pemasaran di PPI Kamal Muara Jakarta Utara.

Sudiyono. 2002 Pemasaran Pertanian.Universitas Muhammadiyah Malang. Malang.

Suyasa I.N. Sondita M.F.A, Nikijuluw V.P.H, dan Monintja D.R. 2007. Status Pemanfaatan Ikan Pelagis Kecil dan Faktor Penentu Efisiensi Usaha Perikanan di Perairan Pantai Utara Jawa. Buletin PSP Vol XVI No. 2. Fakultas Perikanan dan Ilmu Kelautan. IPB. Halaman 232-245.

Triyanti. R. dan N. Shafitri. 2012. Kajian Pemasaran Ikan Lele (Clarias sp) dalam Menunjang Industri Perikanan Budidaya (Studi kasus di Kabupaten Boyolali, Jawa Tengah). KKP Jakarta. Jurnal Sosial Ekonomi Kelautan dan Perikanan Vol. 7 No.2 : 177 - 191.

Yustiarani, A. 2008 Kajian Pendapatan Nelayan dari Usaha Penangkapan Ikan dan bagian Retribusi Pelelangan Ikan di Pangkalan Pendaratan Ikan (PPI) Muara Angke. 